\title{
Surface-enhanced Raman spectroscopy of indanthrone and flavanthrone
}

\author{
Jingjing Chang, ${ }^{\mathrm{a}, \mathrm{b}}$ Maria Vega Cañamares, ${ }^{\mathrm{a}}$ Metin Aydin, ${ }^{\mathrm{C}}$ Wilfried Vetter, ${ }^{\mathrm{d}}$ \\ Manfred Schreiner, ${ }^{d}$ Weiqing $X_{u^{b *}}$ and John R. Lombardi ${ }^{a *, \dagger}$
}

\begin{abstract}
The normal Raman and surface-enhanced Raman scattering (SERS) spectra of flavanthrone and indanthrone were obtained at several excitation wavelengths. The spectral assignments were aided by density functional calculations. Since both molecules have very high symmetry $\left(C_{2 h}\right)$ including a center of inversion, we expect that the modes of $u$ symmetry will be forbidden in the normal Raman spectrum. However, proximity to the surface causes special SERS enhancement of several of the $b_{u}$ modes, along with somewhat weaker enhancement of the $a_{u}$ and $b_{g}$ modes. Copyright (c) 2009 John Wiley \& Sons, Ltd.
\end{abstract}

Supporting information may be found in the online version of this article.

Keywords: Flavanthrone; Indanthrone; SERS; DFT

\section{Introduction}

Carbonyl dyes are of considerable importance in the history and manufacture of natural dyes. On the other hand, anthraquinone dyes were developed early after mauve, the first synthetic dye, was discovered. The higher annulated anthraquinone derivatives are among the most important synthetic carbonyl dyes. ${ }^{[1]}$ The discovery of indanthrone (Fig. 1a, indanthrene blue RS, C.I. Vat blue 4), a blue anthraquinone dye, by Rene Bohn (1862-1922) in 1901 led to the development of the indanthrene vat dyes. ${ }^{[2]}$ Vat dyes are water-insoluble colorants for cotton, which must be reduced (usually by $\mathrm{Na}_{2} \mathrm{~S}_{2} \mathrm{O}_{4} / \mathrm{NaOH}$ ) to their soluble leuco forms in order to be applied from an aqueous dye bath. ${ }^{[3]}$ Among the dyes currently available, indanthrene vat dyes are the ones with the highest levels of light- and wet-fastness properties on cellulosic fibers. However, in spite of their excellent quality, practically no new anthraquinone-based vat dyes have been developed during the past two decades. ${ }^{[1]}$ Indanthrone is made from 1- or 2- amino9,10 -anthraquinone in a $\mathrm{KOH} / \mathrm{H}_{2} \mathrm{O}$ melt at $220-235^{\circ} \mathrm{C}$. Currently, indanthrone pigment is used extensively (total annual production vat pigments $\sim 1000$ ton/year) in the automotive industry and in general industrial paints. ${ }^{[4]}$ Owing to its excellent weather fastness and good transparency, it is especially important for metallic automotive finishes, but it may also be used as colorant for coil coatings, thermoplastics (casting products, fibers) or printing ink for banknotes. ${ }^{[4,5]}$ The yellow dye flavanthrone (indanthrene yellow G, C.I. Vat yellow 1, Fig. 1b) was also discovered by Bohn after heating indanthrone at $300-350^{\circ} \mathrm{C}$. Flavanthrone is still used as a yellow pigment in industrial paints, especially in automobile OEM finishes and in automotive refinishes. Flavanthrone is also used for the coloration of coil coatings, thermoplastics, notably polyacrylic fibers. ${ }^{[4,5]}$ Owing to their high cost, it was not until the 1950 s that (compared to about 400 vat dyes) a few vat pigments (including indanthrone and flavanthrone) have been developed, which met the growing demand of fast pigments for automotive paints. The pigmentation or conditioning process produces a much smaller and more uniform particle size compared to the crude product, which can also be used for surface treatment with resins or surfactants. ${ }^{[4]}$

More recently, several of these dyes have found use in the art world. Because of its high light fastness, flavanthrone is especially favored in artists' colors. ${ }^{[5]}$ In Fig. 2 we illustrate a recent installation in which flavanthrone has been infused into a wax sculpture to produce a luminescent orange glow.

Most of the organic colorants exhibit a rather intense fluorescence emission. This makes their analysis by normal Raman spectroscopy difficult, as the fluorescence background can overwhelm the Raman bands. The use of surface-enhanced Raman spectroscopy (SERS), however, allows the analysis of organic dyes. The great advantage of this technique is the combination of a highly increased Raman sensitivity along with the fluorescence quenching that occurs on rough metallic surfaces. ${ }^{[6,7]}$ Recently, SERS has demonstrated its potential in the analysis of organic natural dyes, mostly anthraquinones ${ }^{[8-11]}$ and flavonoids. ${ }^{[12,13]}$

Few Raman spectra of indanthrone can be found in the literature. For example, the normal Raman spectrum of the pigment at $785 \mathrm{~nm}$ was used to identify the colorant in a cross section of a green automotive paint. ${ }^{[14]}$ The indanthrone pigment applied in

\footnotetext{
Correspondence to: John R. Lombardi, Department of Chemistry, City College of New York, N.Y. 10031, USA. E-mail: lombardi@sci.ccny.cuny.edu Weiging Xu, State Key Laboratory of Supramolecular Structure and Materials, Jilin University, Changchun, 130012, China. E-mail:xuwq@jlu.edu.cn

† This work was partly carried out while one of us (JRL) was a visiting scientist at the Academy of Fine Arts, Vienna.

a Department of Chemistry, City College of New York, N.Y. 10031, USA

b StateKey Laboratory of SupramolecularStructure andMaterials, Jilin University, Changchun, 130012, China

c Department of Chemistry, Faculty of Art and Sciences, Ondokuz Mayis University, 55139, Samsun, Turkey

d Academy of Fine Arts, Schillerplatz 3, Vienna, Austria
} 
<smiles></smiles><smiles>O=c1c2ccccc2c(=O)c2c3[nH]c4c(ccc12)[nH]c1c(=O)c2ccccc2c(=O)c1c4[nH]3</smiles>

Figure 1. Structure of flavanthrone (a) and indanthrone (b).

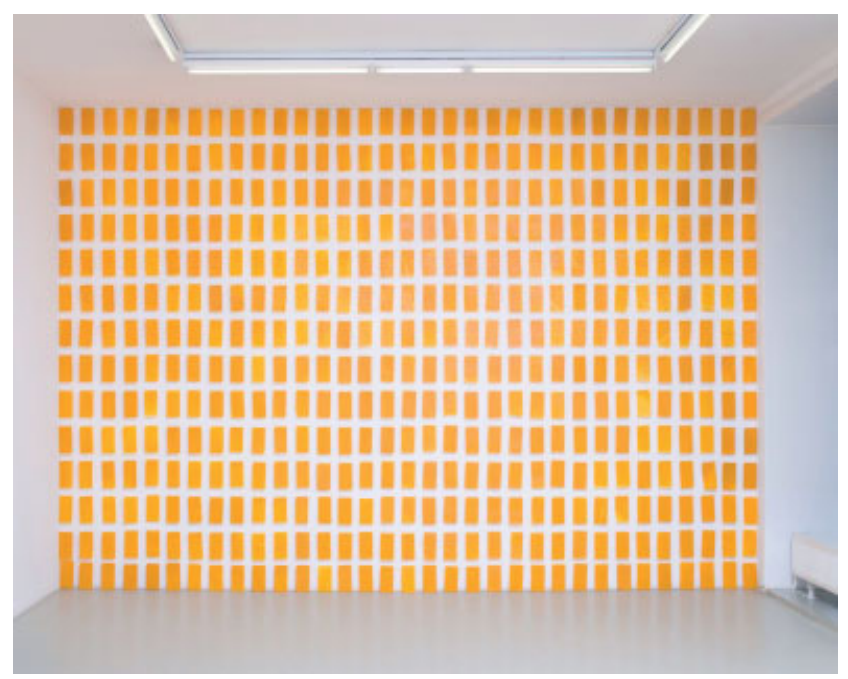

Figure 2. Contemporary Art with flavanthrone. Artist: Johannes Girardoni. Title: 'In Front of the Plane, No. 8', 2007/2008. Installed at: Lukas Feichtner Gallery, Vienna. Made with beeswax, flavanthrone, metal studs, and wood. This installation is composed of individual cast sheets of wax mixed solely with Flavanthrone, installed on two opposing walls perpendicular to the room's natural light source. The sheets are installed about three inches in front of the wall, each individually on a metal stud, allowing light to pass through the wax. The color variation of the panels is caused solely by different thicknesses of the wax, allowing either more or less light to pass through. While installed on the wall, the hue in the room gently shifts all day. Depending on any given light situation the installation's hue changes from golden-orange to a greenish orange.

casein and egg tempera and fresco paintings was also identified by normal Raman spectroscopy with excitation at $633 \mathrm{~nm} \cdot{ }^{[15]} \mathrm{A}$ normal Raman spectrum of flavanthrone pigment has also been reported recently by Colombini and Kaifas. ${ }^{[16]}$ No SERS spectra of these synthetic colorants have been reported.

In this work we present the first SERS analysis of two of the oldest synthetic vat dyes, indanthrone and flavanthrone, together with a density functional theory (DFT) ${ }^{[17]}$ analysis of their vibrational normal modes. The excellent fit of the DFT-generated spectrum with those observed in the normal Raman spectra ensures that our normal mode assignments are correct. These two compounds are also of considerable interest because of their high symmetry (Fig. 1). In addition to a plane of reflection and a two-fold axis of rotation, there is a point of inversion as well. The point group is then $C_{2 h}$. This results in the mutual exclusion rule between infrared and Raman spectra. No spectral lines will appear common to both. However, proximity to the SERS-active surface results in reduced symmetry, causing the introduction of forbidden lines in the Raman spectrum. With our DFT analysis, we are then able to identify these lines and determine their vibrational origin.

\section{Experimental}

\section{Materials}

Indanthrone was obtained from the pigment and dye collection of the Institute of Natural Sciences and Technologies in the Arts of the Academy of Fine Arts in Vienna, Austria. In this collection there are samples of inorganic as well of organic materials, natural and synthetic ones from the end of the 19th to the beginning of the 20th century. In the last few years, all the specimens have been catalogued in an Access-database. About 1400 color materials are available: 400 inorganic pigments and about 1000 organic natural and synthetic samples. The specimen of indanthrone (Monolite Fast Blue 3RS) has the invoice number 1020. It was originally obtained from Imperial Chemical Industries (ICI), England, and is dated August 18, 1953. The sample of flavanthrone (Cibanon Yellow FGN) is a product of Ciba AG, Basel, Switzerland. In order to purify this commercial product, it was rinsed with water and centrifuged three times. Stock solutions of the dyes were prepared fresh each day by dissolving them in water at a concentration of $10^{-4} \mathrm{M}$. Because of their rather poor solubility, ultrasonic dispersion was needed to ensure complete dissolution.

Ag colloid was prepared following the method of Lee and Meisel ${ }^{[18]}$ by means of reduction of silver nitrate (Aldrich 209139; silver nitrate $99.9 \%$ ) with sodium citrate (Aldrich W302600; sodium citrate dihydrate). To further concentrate the colloid for use, $1 \mathrm{ml}$ of the original colloid was centrifuged at $8000 \mathrm{rpm}$ for $5 \mathrm{~min}$. Then, $900 \mu \mathrm{l}$ of the supernatant was discarded and the settled portion was re-suspended with $900 \mu$ l of the original colloid. This process was repeated five times. SERS measurements were made simply by adding a $1-\mu \mathrm{l}$ drop of colloid and $2-\mu \mathrm{l}$ drop of $10^{-4} \mathrm{M}$ sample solution followed by addition of $1 \mu$ of a $0.5 \mathrm{M} \mathrm{KNO}_{3}$ solution. The potassium nitrate was used for aggregating the colloids so they would become active in SERS $\left[{ }^{[18]}\right.$ Raman measurements were made directly from the drop using a microscope.

\section{Instrumentation}

A Bruker Ram II FT Raman-Vertex 70 FTIR microspectrometer was operated for FT Raman measurement, which has a 1064-nm line of an Nd:YAG laser as the excitation source. The resolution was set at $4 \mathrm{~cm}^{-1}$ in the backscattering mode. A liquid nitrogen-cooled $\mathrm{Ge}$ detector was used to collect 1000 scans to obtain a good Raman spectrum. The laser output was kept at $5 \mathrm{~mW}$.

A Bruker Senterra microspectrometer with a long working distance $100 \times$ objective was used to obtain dispersive Raman and SERS spectra at 633 and $785 \mathrm{~nm}$. A 1200 lines/mm grating with a resolution of $3-5 \mathrm{~cm}^{-1}$ and $180^{\circ}$ geometry were employed. The excitations at 633 and the $785 \mathrm{~nm}$ were provided by a $\mathrm{He}-\mathrm{Ne}$ and a diode laser, respectively.

UV-vis spectra were measured with a Cary 50 UV-vis spectrophotometer, using a 1-cm path length ultra-microcuvette. 


\section{Density functional theory (DFT) calculations}

$\mathrm{DFT}^{[17]}$ calculations were performed with Gaussian 03 at the B3LYP level of theory and employing the $6-31+G^{*}$ basis set. The geometry optimization resulted in a planar geometry, and no imaginary wavenumbers were observed in the calculated spectrum. This basis set was chosen to be consistent with earlier work, and because the fit obtained was excellent (see below). In general, vibrational normal mode assignments were based on the best fit comparison of the calculated Raman spectrum with the observed normal Raman spectrum. Where needed, slight scaling of the calculated spectrum was utilized ${ }^{[19-21]}$ (usually 0.98 for flavanthrone and 0.975 for indanthrone). This scaling is commonly needed in DFT calculations of Raman spectra in order to correct for correlation effects incompletely accounted for in DFT. We have found the piecewise scaling to be quite valuable in fitting spectra of related compounds, ${ }^{[12,13]}$ since the correction has a slightly different effect on different bonds, and this is reflected in different regions of the spectrum. In instances where there was spectral congestion, such as in the carbonyl stretch region (near $1600 \mathrm{~cm}^{-1}$ ), the relative intensities of the calculated spectra were matched to those of the observed spectra, so that the most intense calculated lines were assigned to the most intense observed lines.

We have also calculated the electronic transition of these molecules using the time-dependent (TD) density functional theory at the TD-B3LYP/LanI2DZ level. The results of this calculation are given in Tables S1 and S2 (Supporting Information) and discussed below in the examination of the UV-visible absorption spectrum.

\section{Results and Discussion}

\section{UV-visible absorption study of flavanthrone and indanthrone}

Figure 3 shows the UV-visible absorption spectra of $10^{-4} \mathrm{M}$ aqueous solutions of indanthrone and flavanthrone.

The blue dye indanthrone shows various maxima at 605, 640, and $705 \mathrm{~nm}$. On the other hand, the yellow colorant flavanthrone shows a broad adsorption maximum centered at $430 \mathrm{~nm}$. Besides, shoulders at 445,470 , and $510 \mathrm{~nm}$ are seen in that band. We may assign these transitions with the aid of time-dependent DFT calculation (see Tables S1 and S2, Supporting Information).

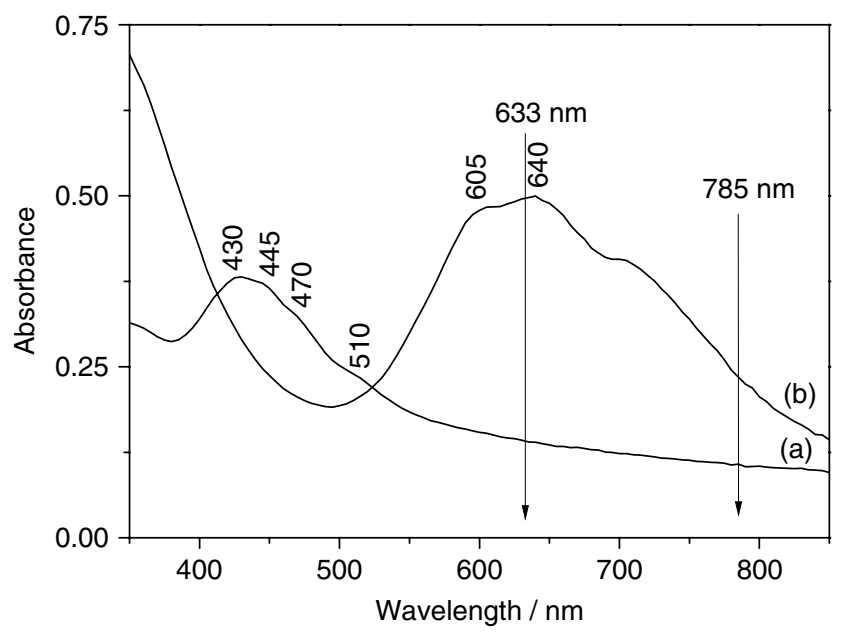

Figure 3. UV-visible absorption spectra of aqueous solutions of flavanthrone (a) and indanthrone (b).
For indanthrone, the calculation shows 16 electronic transitions below $320 \mathrm{~nm}(3.78 \mathrm{eV})$, which result from transitions of the $n$ and/or $\pi$ (nonbonding) orbitals of the ground state to $n^{*}$ and/or $\pi^{*}$ unfilled excited levels. However, only four of the transitions, ${ }^{1} B_{u} \leftarrow{ }^{1} A_{g}$ (xy polarized) are relatively strong dipole-allowed transitions. They are located at $681 \mathrm{~nm}(f=0.599), 382 \mathrm{~nm}$ $(f=0.01) 357 \mathrm{~nm}(f=0.052)$, and $344 \mathrm{~nm}(f=0.085)$. There are also three very weak electronic transitions $(f<0.0001)$ arising from the ${ }^{1} A_{u} \leftarrow{ }^{1} A_{g}$ ( $z$ polarized), transitions at 451, 384, and $336 \mathrm{~nm}$. The remaining transitions are ${ }^{1} B_{g} \leftarrow{ }^{1} A_{g}$, which are strictly symmetry-forbidden. Thus we may easily assign the lowest lying intense ( $f=0.599$ ) transition in indanthrone to the intense ${ }^{1} B_{u} \leftarrow{ }^{1} A_{g}\left(\pi-\pi^{*}\right)$ transition of the calculation. The band at $705 \mathrm{~nm}$ is most likely the origin, and the higher energy bands (640 and $605 \mathrm{~nm}$ ) are most likely to vibrations in the excited state.

For flavanthrone, the TD-DFT calculations show a similar pattern, with the lowest lying ${ }^{1} B_{u} \leftarrow{ }^{1} A_{g}$ transition at $451 \mathrm{~nm}(f=0.663)$ and a weaker ${ }^{1} A_{u} \leftarrow{ }^{1} A_{g}$ transition at $475 \mathrm{~nm}(f=0.0001)$. Once again, we may assign the lowest lying band at $510 \mathrm{~nm}$ to the origin of the former transition, and the higher bands at 470 and $445 \mathrm{~nm}$ to excited state vibrational modes. The weaker ${ }^{1} A_{u} \leftarrow{ }^{1} A_{g}$ is not seen in our spectra.

In this work, laser excitation lines at 633 and $785 \mathrm{~nm}$ are used to record the SERS spectra of both dyes. As the absorption maximum of flavanthrone lies far away from both excitation lines, no molecular resonance enhancement is expected from the yellow dye. On the contrary, the $\mathrm{He}-\mathrm{Ne}$ line at $633 \mathrm{~nm}$ lies near the center of the absorption band of indanthrone. Therefore, an additional molecular resonance enhancement of the Raman bands is expected to be observed in this molecule.

\section{Normal Raman and SERS study of flavanthrone}

In Fig. 4, the FT Raman and the DFT-calculated Raman spectra are compared. By using a 0.98 scaling factor, a very good fit of both the wavenumber and the intensity is obtained. The scaling factor for this molecule was chosen to give the optimum fit in accordance with previous practices. ${ }^{[12]}$ The only exception is the flavanthrone band that appears in the experimental FT Raman spectrum at $1662 \mathrm{~cm}^{-1}$ (the $\mathrm{C}=\mathrm{O}$ stretching region), which does not appear in the calculated one. It is also absent in the SERS spectrum as

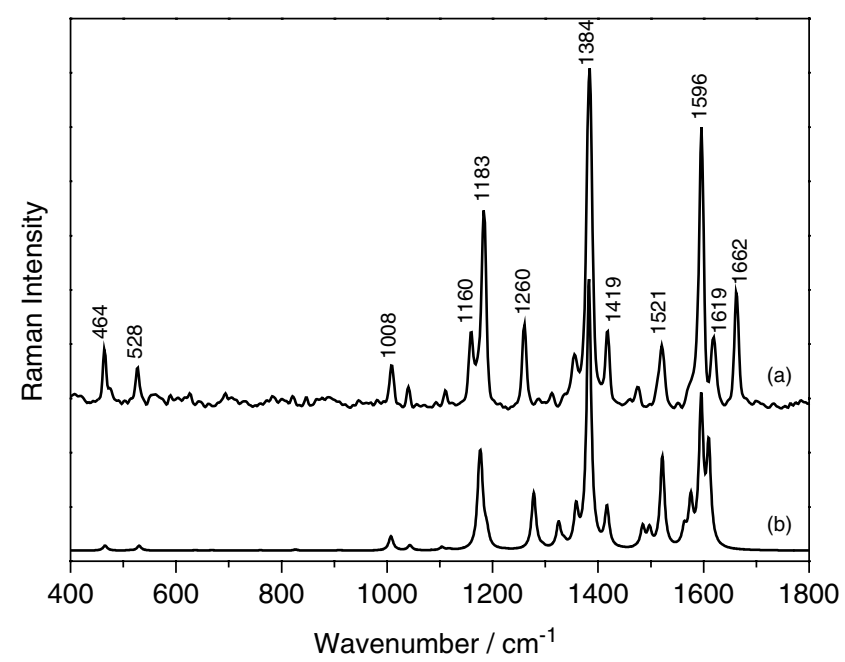

Figure 4. FT Raman (a) and DFT-calculated Raman (b) spectra of flavanthrone. 
well as the solution spectrum. This same behavior has also been observed in the spectra of several flavones. ${ }^{[12,13]}$ The absence of this band in the DFT calculation can be ascribed to the fact that the DFT calculation is carried out considering the molecule in the vacuum, whereas the FT Raman spectrum is of a crystalline sample. The $1662 \mathrm{~cm}^{-1}$ band is most likely due to interactions of the carbonyl stretching modes of adjacent molecules in the crystalline structure, which would be absent in the solution or gas phase spectra.

The main bands of the FT Raman spectrum of the yellow dye are located at 464, 1160, 1183, 1260, 1384, 1419, 1521, 1596, and $1619 \mathrm{~cm}^{-1}$. The corresponding bands observed in the DFTcalculated Raman spectrum are shown at 466, 1166, 1177, 1278, $1383,1417,1522,1595$, and $1609 \mathrm{~cm}^{-1}$. The positions of the bands and the normal modes assigned to those vibrations are compared in Table 1. It can be seen that the majority of the most intense bands in the FT Raman spectrum are the totally symmetric modes $\left(a_{g}\right)$. The most intense FT Raman bands appear at $1183\left(v_{78}\right), 1384\left(v_{94}\right)$, and $1596 \mathrm{~cm}^{-1}\left(v_{110}\right)$, which involve the $v(C=C), v(C=N)_{B}$, and
$\delta(\mathrm{CH})$ vibrations. Other important bands appear at $464\left(v_{26}\right), 1160$ $\left(v_{76}\right), 1260\left(v_{83}\right), 1419\left(v_{96}\right), 1619\left(v_{111}\right)$, and $1662 \mathrm{~cm}^{-1}$. The first band is assigned to the $\delta(C C C)_{D}$ normal mode. The following two are due to $\delta(\mathrm{CH})$ motions. The fourth vibration involves $v(C=N)_{B}$ motion. The last two bands correspond to $v(C=C)$ vibrations.

A comparison of the FT Raman spectrum at $1064 \mathrm{~nm}$ and SERS spectra excited at 633 and $785 \mathrm{~nm}$ is displayed in Fig. 5. The normal Raman spectrum of flavanthrone was recorded at $1064 \mathrm{~nm}$ because when excitation in the visible was employed (633 and $785 \mathrm{~nm}$ ), a high fluorescence emission was obtained, which overlapped with the normal Raman spectrum. Several of the prominent bands, such as those at 1619, 1596, 1419, 1384, 1260,1183 , and $1160 \mathrm{~cm}^{-1}$ are present in both the FT Raman and SERS spectra. Most of them are assigned to $a_{g}$ modes, with the exception of the last one $\left(b_{u}\right)$. The relative intensities of many bands drastically changed when the yellow dye was in contact with the Ag surface. The intensities of the bands at 1619, 1596, 1384 , and $1183 \mathrm{~cm}^{-1}$ decreased considerably. On the other hand, the bands located at $1419,1355,1312,1287,1260$, and $1160 \mathrm{~cm}^{-1}$

\begin{tabular}{|c|c|c|c|c|c|c|}
\hline Mode \# & Description of modes ${ }^{a}$ & Symmetry & DFT & FT Raman & SERS $633 \mathrm{~nm}$ & SERS $785 \mathrm{~nm}$ \\
\hline & & & & $1662(\mathrm{~m})$ & & \\
\hline 114 & $v(\mathrm{C}=\mathrm{O}) / v(\mathrm{CC}) / v(\mathrm{CN})$ & $a_{g}$ & 1621 & $1619(\mathrm{~m})$ & $1628(w)$ & $1621(\mathrm{sh})$ \\
\hline 111 & $v(\mathrm{CC}) / v(\mathrm{C}=\mathrm{O}) / v(\mathrm{CN})$ & $a_{g}$ & 1609 & 1596(s) & $1601(\mathrm{~m})$ & 1598(m) \\
\hline 110 & $v(\mathrm{CC}) / v(\mathrm{C}=\mathrm{O}) / \delta(\mathrm{CH})$ & $a_{g}$ & 1595 & & & \\
\hline 106 & $v(\mathrm{C}=\mathrm{O}) / v(\mathrm{CC}) / v(\mathrm{CN}) / \delta(\mathrm{CH})$ & $a_{g}$ & 1564 & 1552(vw) & $1560(\mathrm{~m})$ & 1555(m) \\
\hline 103 & $v(\mathrm{CC}) / v(\mathrm{CN}) / v(\mathrm{C}=0) / \delta(\mathrm{CH})$ & $a_{g}$ & 1497 & & $1502(w)$ & $1498(w)$ \\
\hline 99 & $\delta(\mathrm{CH})_{\mathrm{A}} / \delta(\mathrm{CC})$ & $a_{g}$ & 1473 & 1475(vw) & $1476(w)$ & $1476(\mathrm{vw})$ \\
\hline 98 & $v(\mathrm{CN})_{\mathrm{B}} / v(\mathrm{CC}) / v(\mathrm{C}=\mathrm{O}) / \delta(\mathrm{CH})$ & $b_{u}$ & 1447 & & $1456(w)$ & $1455(w)$ \\
\hline 96 & $v(\mathrm{CN})_{\mathrm{B}} / v(\mathrm{CC}) / \delta(\mathrm{CCC}) / \delta(\mathrm{CH})$ & $a_{g}$ & 1417 & $1419(\mathrm{~m})$ & 1425 (vs) & 1418(vs) \\
\hline 94 & $v(\mathrm{CN})_{\mathrm{B}} / v(\mathrm{CC}) / \delta(\mathrm{CH})$ & $a_{g}$ & 1383 & 1384(vs) & 1405(sh) & 1401 (vs) \\
\hline 93 & $v(\mathrm{CC}) / \delta(\mathrm{CH})$ & $a_{g}$ & 1358 & $1355(w)$ & $1371(\mathrm{~m})$ & 1368(sh) \\
\hline 89 & $v(\mathrm{CC}) / \nu_{\mathrm{br}}(\mathrm{CCC})_{\mathrm{C}} / \delta(\mathrm{CH})$ & $a_{g}$ & 1325 & 1312(vw) & 1322 (vs) & 1318(s) \\
\hline 85 & $v(\mathrm{CN}) / v(\mathrm{CC}) / \delta(\mathrm{CCC}) / \delta(\mathrm{CH})$ & $b_{u}$ & 1285 & $1287(\mathrm{vw})$ & 1296(vs) & $1285(\mathrm{~m})$ \\
\hline 84 & $\delta(\mathrm{CH}) / \delta(\mathrm{CCC})$ & $a_{g}$ & 1278 & $1260(\mathrm{~m})$ & $1273(\mathrm{~s})$ & $1270(s)$ \\
\hline 81 & $\delta(\mathrm{CH}) / \delta(\mathrm{CCC})$ & $b_{u}$ & 1193 & & $1208(\mathrm{~m})$ & $1207(w)$ \\
\hline 78 & $\delta(\mathrm{CH}) / \delta(\mathrm{CCC}) / \delta(\mathrm{CNC})$ & $a_{g}$ & 1177 & 1183(s) & $1188(w)$ & $1186(w)$ \\
\hline 76 & $\delta(\mathrm{CH}) / \delta(\mathrm{CCC})$ & $b_{u}$ & 1166 & $1160(\mathrm{~m})$ & $1160(s)$ & $1159(\mathrm{~m})$ \\
\hline 72 & $\delta(\mathrm{CH}) / \delta(\mathrm{CCC})$ & $a_{g}$ & 1104 & 1092(vw) & 1089(vw) & $1087(w)$ \\
\hline 71 & $\delta(\mathrm{CH}) / \delta(\mathrm{CCC})$ & $b_{u}$ & 1046 & & 1051(sh) & \\
\hline 70 & $\delta(\mathrm{CH}) / \delta(\mathrm{CCC})$ & $a_{g}$ & 1044 & $1041(\mathrm{vw})$ & 1042(w) & $1035(\mathrm{~m})$ \\
\hline 63 & $\nu_{\mathrm{br}}(\mathrm{CCC}) / \delta(\mathrm{CH})$ & $a_{g}$ & 1007 & $1008(w)$ & 1018(w) & $1017(\mathrm{~m})$ \\
\hline 62 & $\delta(\mathrm{CCC}) / \delta(\mathrm{CH})$ & $b_{u}$ & 1002 & & 1003(sh) & \\
\hline 61 & $\delta(\mathrm{C}=\mathrm{O}) / \delta(\mathrm{CCC})$ & $b_{u}$ & 940 & & $951(w)$ & $949(\mathrm{~m})$ \\
\hline 60 & $\gamma(\mathrm{CH})_{\mathrm{A}} / \gamma(\mathrm{CCC})_{\mathrm{A}}$ & $b_{g}$ & 923 & & $926(\mathrm{~m})$ & $927(\mathrm{~m})$ \\
\hline 57 & $\delta(\mathrm{CNC}) / \delta(\mathrm{C}=\mathrm{O}) / \delta(\mathrm{CCC}) / \delta(\mathrm{CH})$ & $b_{u}$ & 902 & & $902(w)$ & $901(w)$ \\
\hline 54 & $\delta(\mathrm{CCC})$ & $a_{g}$ & 826 & $821(\mathrm{vw})$ & $817(w)$ & $816(w)$ \\
\hline 52 & $\gamma(\mathrm{CH}) / \gamma(\mathrm{CCC})$ & $b_{g}$ & 807 & & 802(sh) & $800(w)$ \\
\hline 48 & $\delta(\mathrm{CNC}) / \delta(\mathrm{CCC})_{\mathrm{C}}$ & $a_{g}$ & 760 & & $766(v w)$ & $767(v w)$ \\
\hline 44 & $\gamma(\mathrm{CCC}) / \gamma(\mathrm{CH})$ & $b_{u}$ & 721 & & $726(v w)$ & 734(vw) \\
\hline 41 & $\gamma(\mathrm{CCC}) / \gamma(\mathrm{CH})$ & $a_{u}$ & 694 & $694(v w)$ & $684(v w)$ & $683(v w)$ \\
\hline 38 & $\delta(\mathrm{CCC}) / \delta(\mathrm{CNC})$ & $a_{g}$ & 667 & & $665(w)$ & $663(w)$ \\
\hline 36 & $\delta(\mathrm{CCC})_{\mathrm{A}} / \delta(\mathrm{CNC})$ & $a_{g}$ & 637 & $626(v w)$ & $637(w)$ & $634(w)$ \\
\hline 29 & $\delta(\mathrm{CNC}) / \delta(\mathrm{CCC})$ & $a_{g}$ & 512 & & $509(v w)$ & $507(\mathrm{~m})$ \\
\hline 26 & $\delta(\mathrm{CCC})_{\mathrm{D}} / \delta(\mathrm{CNC})$ & $a_{g}$ & 466 & $464(\mathrm{~m})$ & $477(w)$ & $476(m)$ \\
\hline
\end{tabular}




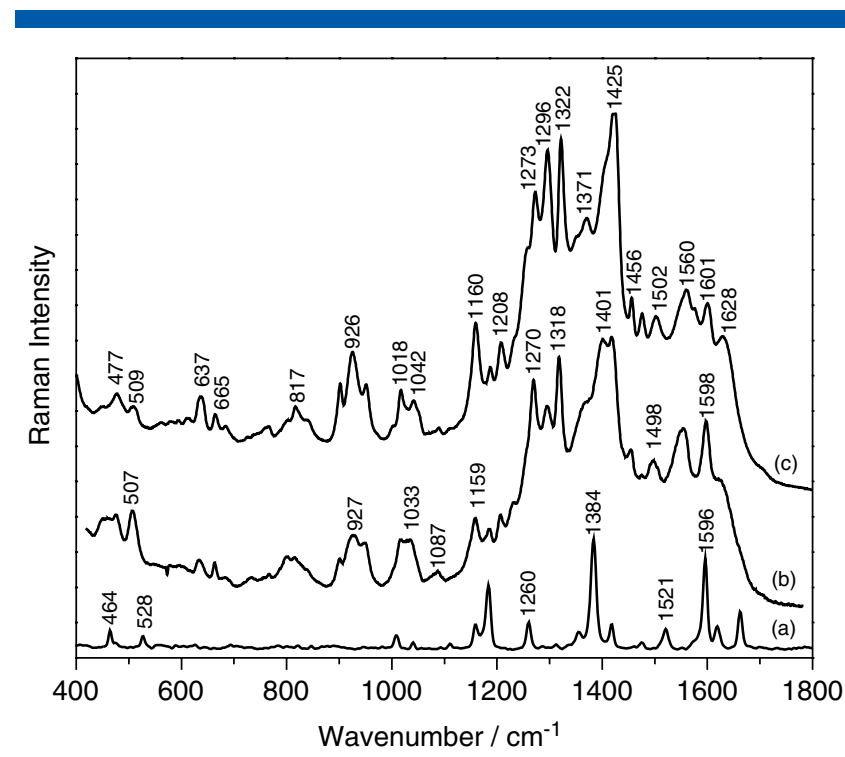

Figure 5. Comparison of the FT Raman at $1064 \mathrm{~nm}$ (a) and SERS spectra of flavanthrone $\left(10^{-4} \mathrm{M}\right)$ with excitation at $785 \mathrm{~nm}$ (b) and $633 \mathrm{~nm}$ (c).

increased in intensity considerably and shifted to some extent while on the surface of the Ag nanoparticles. Moreover, the bands at $1502,1456,1208,951,926$, and $902 \mathrm{~cm}^{-1}$ appear in the SERS spectrum of flavanthrone but not in the FT Raman spectrum. Only the first one (at $1502 \mathrm{~cm}^{-1}$ ) involves a totally symmetric mode $\left(a_{g}\right)$. All others are due to the non-totally-symmetric modes $b_{u}$ or $b_{g}$. The appearance of non-totally-symmetric modes when the indanthrone is adsorbed onto the Ag nanoparticles suggests a charge transfer contribution to the SERS enhancement for that system.

There are few changes in the positions of most bands when the molecule is on Ag nanoparticles. The largest shifts are seen in the normal Raman bands at 1384, 1260, 1008, 694, 626, and $464 \mathrm{~cm}^{-1}$ (Fig. 5a), which are seen at 1401, 1368, 1270, 1017, 683, 634, and $476 \mathrm{~cm}^{-1}$ in the SERS spectrum registered at $785 \mathrm{~nm}$ (Fig. 5c). All these bands are assigned to totally symmetric $a_{g}$ modes.

The SERS spectra recorded with 633 and $785 \mathrm{~nm}$ excitation show the same spectral profile. However, some differences can be seen, mainly in the relative intensity of the bands in the region $1000-1450 \mathrm{~cm}^{-1}$. With excitation at $633 \mathrm{~nm}$, a strong band with two maxima at 1401 and $1418 \mathrm{~cm}^{-1}$ and a shoulder at $1368 \mathrm{~cm}^{-1}$ is seen. However, with 785-nm excitation, two bands are observed: a very intense one at $1425 \mathrm{~cm}^{-1}$ with a shoulder at $1405 \mathrm{~cm}^{-1}$ and a medium one at $1371 \mathrm{~cm}^{-1}$. In the three bands between 1250 and $1350 \mathrm{~cm}^{-1}$, some differences are found. In the spectrum registered at $633 \mathrm{~nm}$, the band at the center $\left(1285 \mathrm{~cm}^{-1}\right)$ is the least intense, while the corresponding one in the SERS spectrum with $785 \mathrm{~nm}$ excitation is almost as intense as the one at $1322 \mathrm{~cm}^{-1}$. Finally, around $1020 \mathrm{~cm}^{-1}$, a band with two maxima of the same intensity $\left(1018\right.$ and $\left.1033 \mathrm{~cm}^{-1}\right)$ is shown in the spectrum recorded at $633 \mathrm{~nm}$. On the contrary, two bands with different intensities (1018 and $1042 \mathrm{~cm}^{-1}$ ) are seen in the SERS spectrum with 785-nm excitation.

\section{Normal Raman and SERS study of indanthrone}

The normal Raman and the DFT-calculated Raman spectra are shown in Fig. 6. The DFT wavenumbers have been scaled by a factor of 0.975 . As can be seen, the fit is excellent and we have therefore great confidence in the assignments. The main

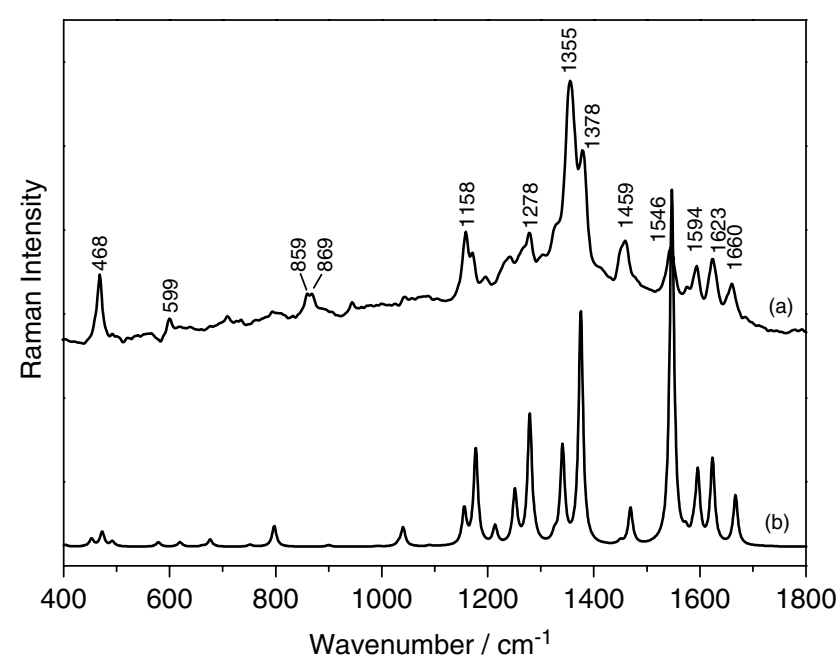

Figure 6. FT Raman (a) and DFT-calculated Raman (b) spectra of indanthrone.

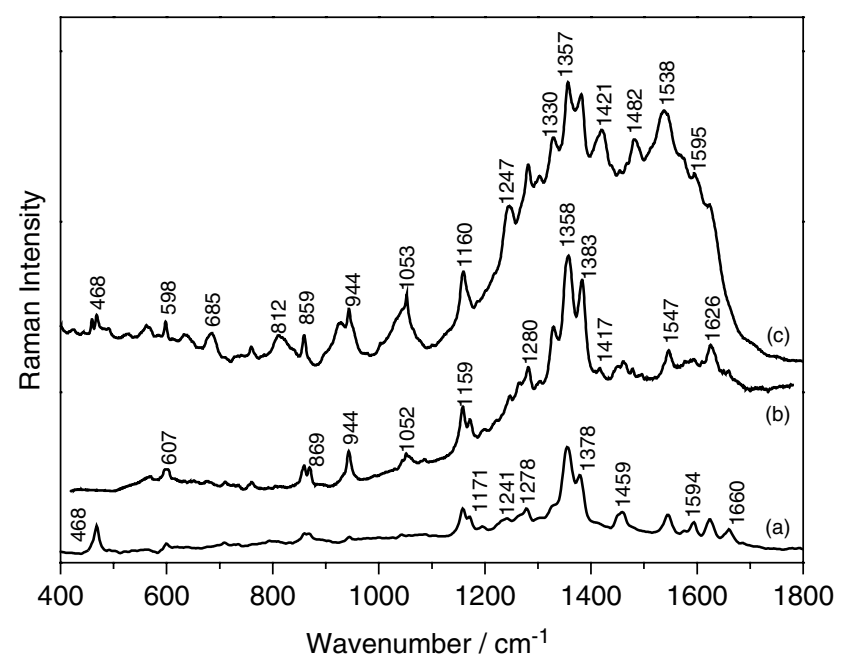

Figure 7. Comparison of the FT Raman at $1064 \mathrm{~nm}$ (a) and SERS spectra of indanthrone $\left(10^{-4} \mathrm{M}\right)$ with excitation at $785 \mathrm{~nm}(\mathrm{~b})$ and $633 \mathrm{~nm}$ (c).

bands of the FT Raman spectrum of the blue dye are located at $468,1158,1355,1378,1459,1546$, and $1623 \mathrm{~cm}^{-1}$, which correspond to the bands shown in the DFT-calculated Raman spectrum at $473,1155,1341,1376,1469,1547$, and $1623 \mathrm{~cm}^{-1}$. The experimental and calculated wavenumbers are tabulated in Table 2 along with the assigned normal modes and a brief description of the major vibrational displacements that contribute to the assigned mode. The most intense bands in the FT Raman spectrum, at $1355\left(v_{102}\right)$ and $1378 \mathrm{~cm}^{-1}\left(\nu_{103}\right)$, involve the $v(C C)$, $\delta(\mathrm{CH})$, and $\delta(\mathrm{C}=\mathrm{O})$ vibrations. Other important bands appear at $468\left(v_{33}\right), 1158\left(v_{84}\right), 1278\left(v_{96}\right), 1459\left(v_{108}\right), 1546\left(v_{113}\right), 1594\left(v_{120}\right)$, $1623\left(v_{121}\right)$, and $1660 \mathrm{~cm}^{-1}\left(v_{124}\right)$. The first band is assigned to the $\delta(C C C)$ normal mode, whereas the second one involves $\delta(\mathrm{CH})$ motion. The following five bands are due to $v(C=C)$ vibrations, and the last one corresponds to a $v(C=0)$ motion. As it can be seen in Table 2, the most intense bands in the FT Raman spectrum are assigned to totally symmetric modes $\left(a_{g}\right)$.

The comparison of the FT Raman and the SERS spectra of indanthrone are displayed in Fig. 7. The SERS spectra were obtained with 633 and $785 \mathrm{~nm}$ excitation lines. 
Table 2. Wavenumbers (in $\mathrm{cm}^{-1}$ ) and assignments of the Raman and SERS bands of indanthrone. The DFT wavenumbers are scaled by a factor of 0.975

\begin{tabular}{|c|c|c|c|c|c|c|}
\hline Mode \# & Description of modes ${ }^{a}$ & Symmetry & DFT & FT Raman & SERS $633 \mathrm{~nm}$ & SERS $785 \mathrm{~nm}$ \\
\hline 124 & $v(\mathrm{C}=0) / v(\mathrm{CC})$ & $a_{g}$ & 1667 & $1660(w)$ & & $1660(w)$ \\
\hline 121 & $v(\mathrm{C}=\mathrm{O}) / v(\mathrm{CC}) / \delta(\mathrm{NH})$ & $a_{g}$ & 1623 & $1623(\mathrm{~m})$ & 1624(sh) & $1626(\mathrm{~m})$ \\
\hline 120 & $v(\mathrm{CC}) / \delta(\mathrm{NH}) / \delta(\mathrm{CH})$ & $a_{g}$ & 1596 & 1594(w) & 1595(sh) & 1593(vw) \\
\hline 115 & $v(\mathrm{CC}) / \delta(\mathrm{NH}) / \delta(\mathrm{CH})$ & $a_{g}$ & 1573 & 1577(sh) & 1569(sh) & \\
\hline 113 & $v(\mathrm{CC})_{\mathrm{C}} / v(\mathrm{CN}) / \delta(\mathrm{NH}) / \delta(\mathrm{CH}) / v(\mathrm{C}=\mathrm{O})$ & $a_{g}$ & 1547 & $1546(\mathrm{~m})$ & 1538(s) & $1547(\mathrm{~m})$ \\
\hline 111 & $v(\mathrm{CC})_{\mathrm{C}} / v(\mathrm{C}=\mathrm{O}) / \delta(\mathrm{NH}) / \delta(\mathrm{CH})$ & $b_{u}$ & 1485 & & 1482(m) & $1496(w)$ \\
\hline 108 & $v(\mathrm{CC}) / \delta(\mathrm{CH})$ & $a_{g}$ & 1469 & $1459(\mathrm{~m})$ & 1469(sh) & $1460(w)$ \\
\hline 106 & $v(\mathrm{CC}) / \delta(\mathrm{CH})$ & $a_{g}$ & 1451 & & $1455(w)$ & 1450 (sh) \\
\hline 104 & $v(\mathrm{CC}) / \delta(\mathrm{CH}) / \delta(\mathrm{NH})$ & $b_{u}$ & 1400 & $1413(v w)$ & $1421(\mathrm{~m})$ & $1417(w)$ \\
\hline 103 & $v(\mathrm{CC}) / \delta(\mathrm{NH}) / \delta(\mathrm{CH}) / \delta(\mathrm{C}=\mathrm{O})$ & $a_{g}$ & 1376 & $1378(s)$ & 1382(s) & 1383(s) \\
\hline 102 & $v(\mathrm{CC}) / \delta(\mathrm{CH}) / \delta(\mathrm{C}=\mathrm{O})$ & $a_{g}$ & 1341 & 1355(vs) & $1357(v s)$ & 1358(vs) \\
\hline 101 & $v(\mathrm{CC}) / \nu(\mathrm{CN}) / \delta(\mathrm{NH})$ & $a_{g}$ & 1326 & 1330(sh) & $1330(\mathrm{~m})$ & $1330(\mathrm{~m})$ \\
\hline 98 & $v(\mathrm{CC}) / \delta(\mathrm{CCC})_{\mathrm{C}} / \delta(\mathrm{CH}) / \delta(\mathrm{C}=\mathrm{O})$ & $b_{u}$ & 1304 & 1305(sh) & $1303(w)$ & 1304(vw) \\
\hline 95 & $v(\mathrm{CC}) / \nu_{\mathrm{br}}(\mathrm{CCC})_{\mathrm{A}} / \delta(\mathrm{NH}) / \delta(\mathrm{CH}) / \delta(\mathrm{C}=\mathrm{O})$ & $a_{g}$ & 1279 & $1278(w)$ & $1282(\mathrm{~m})$ & $1282(\mathrm{~m})$ \\
\hline 94 & $v(\mathrm{CC}) / \delta(\mathrm{CCC})_{\mathrm{C}} / \delta(\mathrm{NH}) / \delta(\mathrm{CH}) / \delta(\mathrm{C}=\mathrm{O})$ & $b_{u}$ & 1262 & & & $1265(\mathrm{sh})$ \\
\hline 91 & $v(\mathrm{CN}) / \delta(\mathrm{NH}) / \delta(\mathrm{CH})$ & $a_{g}$ & 1251 & $1241(v w)$ & $1247(\mathrm{~m})$ & $1248(\mathrm{sh})$ \\
\hline 90 & $v(\mathrm{CC}) / \nu(\mathrm{CN}) / \delta(\mathrm{NH})$ & $b_{u}$ & 1217 & & & $1221(\mathrm{sh})$ \\
\hline 87 & $v_{\mathrm{br}}(\mathrm{CCC}) / \nu(\mathrm{CC}) / \delta(\mathrm{CH})$ & $a_{g}$ & 1177 & 1172(sh) & & $1172(w)$ \\
\hline 84 & $\Delta(\mathrm{CH})$ & $a_{g}$ & 1155 & $1158(\mathrm{~m})$ & $1160(\mathrm{~m})$ & $1159(\mathrm{~m})$ \\
\hline 79 & $v(\mathrm{CC}) / v_{\mathrm{br}}(\mathrm{CCC})_{\mathrm{D}} / \delta(\mathrm{CH})$ & $a_{g}$ & 1040 & 1043(vw) & 1053(m) & 1052(w) \\
\hline 75 & $v_{\mathrm{br}}(\mathrm{CCC})_{\mathrm{AD}} / \delta(\mathrm{CCC}) / \delta(\mathrm{NH}) / \delta(\mathrm{CH}) / \delta(\mathrm{C}=\mathrm{O})$ & $a_{g}$ & 993 & $944(v w)$ & 944(m) & $944(m)$ \\
\hline 68 & $\Delta(\mathrm{CCC}) / \delta(\mathrm{C}=\mathrm{O}) / \delta(\mathrm{NH}) / \delta(\mathrm{CH})$ & $a_{g}$ & 900 & & $929(\mathrm{~m})$ & \\
\hline 65 & $\Delta(\mathrm{CCC}) / \delta(\mathrm{C}=\mathrm{O}) / \delta(\mathrm{CN})$ & $b_{u}$ & 883 & $869(w)$ & & $869(w)$ \\
\hline 64 & $v_{\mathrm{br}}(\mathrm{CCC})_{\mathrm{D}} / \delta(\mathrm{CCC}) / \delta(\mathrm{NH}) / \delta(\mathrm{C}=\mathrm{O})$ & $b_{u}$ & 858 & $859(w)$ & $859(w)$ & $859(w)$ \\
\hline 61 & $v_{\mathrm{br}}(\mathrm{CCC})_{\mathrm{D}} / \delta(\mathrm{CCC}) / \delta(\mathrm{C}=\mathrm{O})$ & $a_{g}$ & 798 & 794(vw) & $812(w)$ & $805(v w)$ \\
\hline 55 & $\Delta(\mathrm{CCC}) / \delta(\mathrm{C}=\mathrm{O}) / \delta(\mathrm{NH})$ & $a_{g} / a_{u}$ & $752 / 778$ & & $760(w)$ & $761(w)$ \\
\hline 49 & $\Gamma(\mathrm{CH}) / \gamma(\mathrm{NH}) / \gamma(\mathrm{CC}) / \gamma(\mathrm{C}=\mathrm{O})$ & $a_{u} / b_{g}$ & 710 & 709(vw) & & $710(v w)$ \\
\hline 47 & $\Delta(\mathrm{CCC}) / \delta(\mathrm{C}=\mathrm{O})$ & $a_{g}$ & 677 & & $685(w)$ & $678(v w)$ \\
\hline 41 & $\Delta(\mathrm{CNC}) / \delta(\mathrm{CCC})$ & $a_{g}$ & 619 & $599(v w)$ & $598(w)$ & $607(w)$ \\
\hline 39 & $\Delta(\mathrm{CCC})$ & $a_{g}$ & 579 & & $562(v w)$ & $569(w)$ \\
\hline 34 & $\Delta(\mathrm{CCC})$ & $a_{g}$ & 491 & & $491(w)$ & \\
\hline 33 & $\Delta(\mathrm{CCC}) / \delta(\mathrm{CNC})$ & $a_{g}$ & 473 & $468(m)$ & $468(w)$ & \\
\hline
\end{tabular}

The normal Raman spectrum at $1064 \mathrm{~nm}$ (Fig. 7a) shows features similar to the SERS spectrum at $785 \mathrm{~nm}$ (Fig. 7b). On the contrary, a number of new bands and enhancement of other bands in the high wavenumber region are observed in the SERS spectrum at $633 \mathrm{~nm}$ of the $10^{-4} \mathrm{M}$ aqueous solution of indanthrone on $\mathrm{Ag}$ nanoparticles (Fig. 7c). These differences can be explained as due to the resonance Raman effect that takes place in indanthrone when excited at $633 \mathrm{~nm}$.

The bands at 468,1594 , and $1660 \mathrm{~cm}^{-1}$ in the FT Raman spectrum decrease in intensity in the SERS spectrum of the blue dye at $785 \mathrm{~nm}$. On the contrary, other bands are relatively enhanced due to the interaction of indanthrone with the Ag surface. These are the ones located at 607, 944, 1051, 1280, 1304, 1330, 1358, 1383 , and $1415 \mathrm{~cm}^{-1}$. Finally, some bands are observed only in the SERS spectrum (Fig. 7b), such as the ones at 569, 678, 761, 1221, 1265 , and $1496 \mathrm{~cm}^{-1}$. The first three, which are the most intense of the former bands, are assigned to the non-totally-symmetric mode $b_{u}$. The other three, which show very weak intensities, are assigned to the totally symmetric mode $\left(a_{g}\right)$.

The main differences between the SERS (Fig. 7b) and surface enhanced resonance Raman spectroscopy (SERRS) (Fig. 7c) spectra are the relative enhancement of the bands at 468,685 , $812,929,944,1053,1160,1247,1421,1482$, and $1538 \mathrm{~cm}^{-1}$. Most of these are assigned to $a_{g}$ modes. Only two (1421 and $1482 \mathrm{~cm}^{-1}$ ) correspond to $b_{u}$ symmetry. The enhancement of the totally symmetric modes $\left(a_{g}\right)$ in the SERS spectrum at $633 \mathrm{~nm}$ with respect to that at $785 \mathrm{~nm}$ can be explained by taking into account the additional enhancement due to the molecular resonance of indanthrone at $633 \mathrm{~nm}$ (Fig. 3).

\section{Discussion}

\section{The Raman enhancement}

We should also note that several of the vibrational modes that are enhanced most by adsorption of the molecules to the surface are normally Raman forbidden non-totally-symmetric lines. They are by and large of $b_{u}$ (out-of-plane) symmetry, although a few lines of $b_{g}$ and $a_{u}$ symmetry are also weakly enhanced. Assuming that the molecules lie flat on the metal surface, this can be explained by the charge-transfer theory of SERS, ${ }^{[22]}$ which holds that those non-totally-symmetric bands that are most enhanced are due to interaction of a charge-transfer transition with a resonant or 
nearby allowed molecular transition. The nearest allowed optical transition in this case is the $\pi-\pi^{*}$ transition (symmetry $B_{u}$ ) at 430 and $640 \mathrm{~nm}$ for flavanthrone and indanthrone, respectively (see Fig. 3). Using the Herzberg-Teller surface selection rules derived in Ref. [22], we expect vibrations of symmetry $b_{u}$ to be most strongly SERS-enhanced. The TD-DFT theory also predicts optical transitions to $A_{u}$ and $B_{g}$ states. Those to $A_{u}$ states are considerably weaker than the $B_{u}$ transition and those to $B_{g}$ are symmetryforbidden. The oscillator strengths of these optical transitions are in the order $f\left(B_{u}\right)>f\left(A_{u}\right)>f\left(B_{g}\right)$. We thus expect weaker SERS enhancements in bands of these symmetries, although the $b_{g}$ bands, which should be strictly forbidden, are most likely weakly allowed because of symmetry-lowering near the surface. Note the theory also indicates that in any case the totally symmetric $\left(a_{g}\right)$ lines will always be enhanced strongly. The Herzberg-Teller selection rules therefore indicate that the order of SERS enhancements should be $a_{g}>b_{u}>a_{u}>b_{g}$, and this is as observed.

\section{Acknowledgements}

We would like to thank Dr. Marco Leona of the Metropolitan Museum of Art for valuable assistance in this research. Thanks are also due to Prof. Ron Birke and Ms. Paula Harper of The City College of New York. We also appreciate the helpful discussions with Mr. Johannes Girardoni in suggesting this research.

We are indebted to the National Institute of Justice (Department of Justice Award \#2006-DN-BX-K034) and the City University Collaborative Incentive program (\#80209). This work was further supported by the National Science Foundation under Cooperative Agreement No. RII-9353488, grant No. CHE-0091362, CHE-0345987 and grant number ECS0217646 and by the City University of New York PSC-BHE Faculty Research Award Program. We are also indebted to the National Science Foundation Grant \# IMR 0526926, which supplied the Bruker Senterra/Ramanscope combined Dispersive Raman/FT Raman spectrometer. This work is also supported by the National Natural Science Foundation of China (NSFC 20773045 and 20627002) and the Programme of Introducing Talent of Discipline to Universities ('111' Project, B06009).

\section{Supporting information}

Supporting information may be found in the online version of this article.

\section{References}

[1] H. Zollinger, Color Chemistry: Synthesis, Properties, and Applications of Organic Dyes and Pigments (3rd revised edn), Helvetia Chimica Acta, Wiley-VCH, Zürich, 2003.
[2] A. von Nagel, Indanthren, Komplexfarbstoffe, Tenside. Schriftenreihe des Firmenarchivs der Badischen Anilin- \& Soda-Fabrik AG, 1968.

[3] E. R. Riegel, J. A. Kent, in Riegel's Handbook of Industrial Chemistry (10th edn) (Ed.: J. A. Kent), Springer, New York, 2003.

[4] P. A. Lewis, Pigment Handbook, vol. 1, Properties and Economics (2nd edn), A Wiley-Interscience Publication, John Wiley \& Sons: New York, 1988.

[5] W. Herbst, K. Hunger, Industrial Organic Pigments. Production, Properties, Applications (3rd Completely Revised edn), Wiley-VCH Verlag GmbH \& Co. KGaA: Weinheim, 2004.

[6] R. L. Birke, J. R. Lombardi, Surface enhanced Raman scattering, in Spectroelectrochemistry: Theory and Practice (Ed.: R. J. Gale), Plenum: New York, 1988, pp 263.

[7] M. Moskovits, Rev. Mod. Phys. 1985, 57, 783.

[8] B. Guineau, V. Guichard, ICOM Committee for Conservation: 8th Triennial Meeting, vol. 2, The Getty Conservation Institute: Marina del Rey: Sidney, 1987, p 659

[9] M. V. Cañamares, J. V. Garcia-Ramos, C. Domingo, S. SanchezCortes, J. Raman Spectrosc. 2004, 35, 921.

[10] M. V. Cañamares, J. V. Garcia-Ramos, C. Domingo, S. SanchezCortes, Vib. Spectrosc. 2006, 40, 161.

[11] M. Leona, J. Stenger, E. Ferloni, J. Raman Spectrosc. 2006, 37, 981.

[12] T. Teslova, C.Corredor, R. Livingstone, T. Spataru, R. L. Birke, J. R. Lombardi, M. V. Cañamares, M. Leona, J. Raman Spectrosc. 2007, 38,802 .

[13] C.Corredor, T. Teslova, M. V.Cañamares, Z.Chen, J.Zhang, J. R. Lombard, M. Leona, Vib. Spectrosc. 2009, 49, 190.

[14] J.De Gelder, P. Vandenabeele, F. Govaert, L. Moens, J. Raman Spectrosc. 2005, 36, 1059.

[15] G. Burrafat, M. Calabrese, A.Consentino, A. M. Gueli, S. O. Troja, A. Zuccarello, J. Raman Spectrosc. 2004, 35, 879.

[16] A. Colombini, D. Kaifas, Characterization of some orange and yellow organic and fluorescent pigments by Raman spectroscopy, in Presentation at IRUG-8 Conference in Vienna, Austria, March 26-29, 2008.

[17] M. J. Frisch, G. W. Trucks, H. B. Schlegel, G. E. Scuseria, M. A. Robb, J.R.Cheeseman, J.A. Montgomery Jr, T. Vreven, K. N. Kudin, J.C. Burant, J.M. Millam, S. S. Iyengar, J.Tomasi, V. Barone, B. Mennucci, M. Cossi, G. Scalmani, N. Rega, G. A. Petersson, H. Nakatsuji, M. Hada, M. Ehara, K. Toyota, R. Fukuda, J. Hasegawa, M. Ishida, T. Nakajima, Y. Honda, O. Kitao, H. Nakai, M. Klene, X. Li, J.E. Knox, H.P. Hratchian, J.B. Cross, V. Bakken, C. Adamo, J. Jaramillo, R. Gomperts, R. E. Stratmann, O. Yazyev, A. J. Austin, R. Cammi, C. Pomelli, J.W. Ochterski, P. Y. Ayala, K. Morokuma, G. A. Voth, P. Salvador, J.J. Dannenberg, V. G. Zakrzewski, S. Dapprich, A.D. Daniels, M.C. Strain, O. Farkas, D. K. Malick, A.D. Rabuck, K. Raghavachari, J. B. Foresman, J. V. Ortiz, Q.Cui, A. G. Baboul, S.Clifford, J.Cioslowski, B. B. Stefanov, G. Liu, A. Liashenko, P. Piskorz, I. Komaromi, R. L. Martin, D. J. Fox, T. Keith, M. A. Al-Laham, C. Y. Peng, A. Nanayakkara, M. Challacombe, P.M.W. Gill, B. Johnson, W. Chen, M. W. Wong, C. Gonzalez, J. A. Pople, Gaussian 03, Revision C.02, Gaussian, Inc.: Wallingford, $C T, 2004$.

[18] P. C. Lee, D. Meisel, J. Phys. Chem. 1982, 86, 3391.

[19] G. Rauhut, P. Pulay, J. Phys. Chem. 1995, 99, 3093.

[20] P. Pulay, G. Fogarasi, G. Pongor, J. E. Boggs, A. Vargha, J. Am. Chem. Soc. 1983, 105, 7037.

[21] J. Neugebauer, B. A. Hess, J. Chem. Phys. 2003, 118, 7215.

[22] J. R. Lombardi, R. L. Birke, J. Phys. Chem. C 2008, 112, 5605, $10.1021 /$ jp800167v. 